\title{
Fatigue crack propagation of D6AC laser welds
}

\author{
L.W. Tsay*, C.S. Chung* and C. Chent \\ *Institute of Materials Engineering, National Taiwan Ocean University, Keelong, \\ Taiwan, R.O.C. \\ tInstitute of Materials Science and Engineering, National Taiwan University, \\ Taipei, Taiwan, R.O.C. \\ (Received 25 September 1995; accepted 17 June 1996)
}

\begin{abstract}
Fatigue crack growth tests of D6AC steel plates and laser welds were performed. The effect of tempering temperatures on fatigue and mechanical properties of the material was also conducted. The results indicated that the strength of weldments was lower than that of the steel plates, with the joint efficiency of $>92 \%$. The tough structure consisted of lower bainite and tempered martensite was formed in the weld metal (WM) and the heat-affected zone, owing to a preheat of $225^{\circ} \mathrm{C}$ were employed during welding. As a result, higher impact values and lower fatigue crack growth rates (FCGRs) of these regions were expected in the subsequent postweld heat treatments (PWHTs). In general, the FCGRs in the WM and the HAZ of laser welds were lower than those in the base metal for the same stress intensity factor range $(\Delta K)$, regardless of distinct PWHTs. The fatigue-fractured surfaces associated with them revealed transgranular and intergranular fracture modes. The zigzag nature of the crack path, particularly in the WM, could contribute to the retardation of fatigue crack propagation. Copyright (C) 1997 Elsevier Science Limited.
\end{abstract}

(Keywords: fatigue crack growth rate; DGAC steel; laser welding)

\section{INTRODUCTION}

D6AC, a high strength steel, has been used extensively in the fabrication of aircrafts and rocket cases. ${ }^{1,2}$ It is a medium carbon low alloy steel with high hardenability. The isothermal transformation diagram ${ }^{1}$ shows that there is a deep and broad austenitic bay for the steel. D6AC is very sensitive to hydrogen-induced cracking, ${ }^{3,4}$ so that the presence of hydrogen as well as the formation of untempered martensite should be minimized. Consequently, the proper selection of preheating and postweld heat treating are required to reduce the cracking susceptibility of the weldment. ${ }^{5-9}$

When an intense laser beam is focused on the workpiece, the material under the beam evaporates and generates a cavity, called a keyhole. ${ }^{10}$ The characteristics of laser welding include deep penetration, narrow bead width and minimum distortion etc., which are typically a keyhole weld made by high power density welding processes. Laser welding is a mature technology to produce high quality welds which are comparable in quality with those of electron beam welds, especially in thin sections. The ability of lasers to weld in air is the major advantage over electron beam welding which generally requires modest vacuum conditions. Recently, laser welding has become of great interest in various industries for precision welds. The low heat input of such a process caused the formation of narrow heat-affected zones (HAZ) as well as the fusion zone which is also called the weld metal (WM) in the text. Therefore, less attention has been paid to the characteristics of fatigue crack growth rates (FCGRs) in these small regions of the weld.

During the period of stable crack propagation, the empirical power law relationship as proposed by Paris and Erdogan" is given by

$$
\mathrm{d} a / \mathrm{d} N=\mathrm{c}(\Delta K)^{\mathrm{m}}
$$

where $\mathrm{d} a / \mathrm{d} N$ is the FCGR, $\Delta K$ is the stress intensity factor range, $\mathrm{c}$ and $\mathrm{m}$ are the material constants. The result of such tests can be used to predict the fatigue life of a component. Most of the research works were concentrated on the brittle fracture of welded structures, ${ }^{12,13}$ and the decrease of fracture toughness usually

Table 1 Laser welding parameters used in the experiment

\begin{tabular}{ll}
\hline Laser power & $3000 \mathrm{~W}$ \\
Travel speed & $1000 \mathrm{~mm} \mathrm{~min}^{-1}$ \\
Focal lens & $\mathrm{ZnSe}$ \\
Focal length & $190.5 \mathrm{~mm}$ \\
Focal point & $0.5 \mathrm{~mm}$ underfocus \\
& $(0.5 \mathrm{~mm}$ below the surface $)$ \\
Plasma assist gas flow rate & $25 \mathrm{lpm} \mathrm{He}$ \\
Backing gas flow rate & $25 \mathrm{lpm} \mathrm{Ar}$ \\
Preheat & $225^{\circ} \mathrm{C}$ \\
\hline
\end{tabular}


occurred in the HAZ. ${ }^{14-16}$ In order to reduce FCGRs in either $\mathrm{HAZ}$ or WM, the applications of preheating together with postweld heat treatments (PWHTs) are of particular importance.

This work investigates the influence of various PWHTs on the fatigue and mechanical properties of D6AC steel plates and laser welds. The FCGRs of laser welds in two different directions, i.e. normal and parallel to the welding directions, were determined.
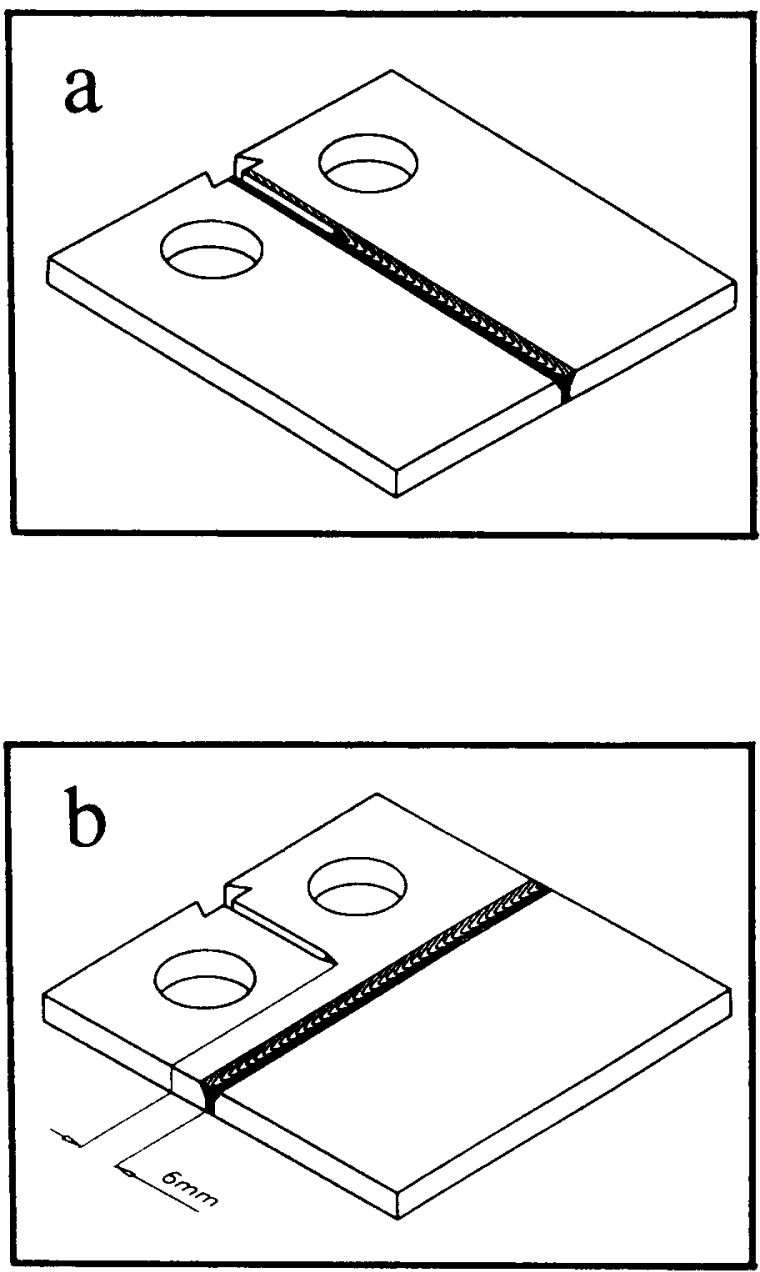

Figure 1 Schematic representation showing: (a) P-Weld; and (b) $\mathrm{N}$-Weld $\mathrm{CT}$ specimens employed in the fatigue crack growth test
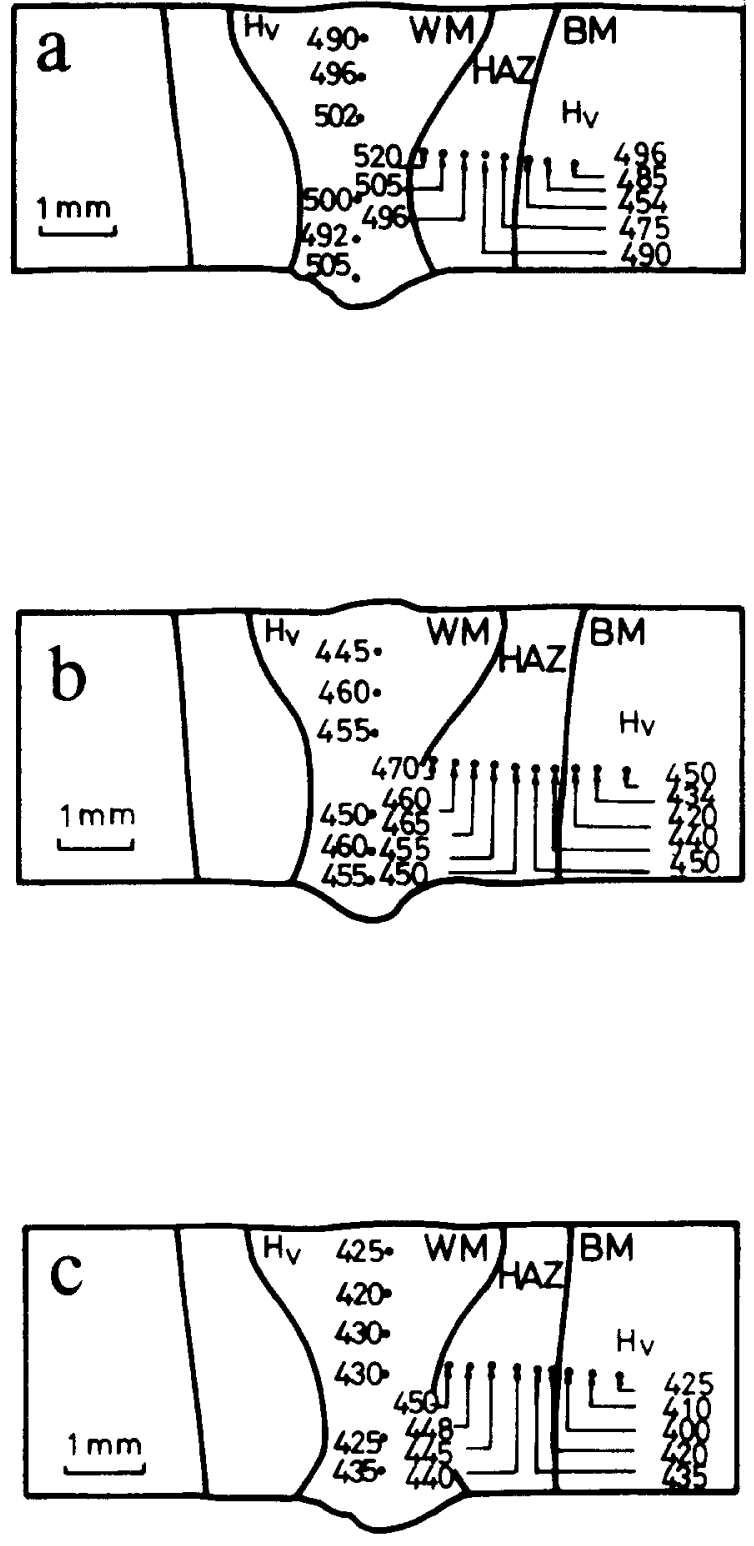

Figure 2 Schematic diagrams showing microhardness distribution in the welds after (a) $400^{\circ} \mathrm{C}$, (b) $500^{\circ} \mathrm{C}$ and (c) $600^{\circ} \mathrm{C}$ PWHT: treatment for $2 \mathrm{~h}$

Table 2 Mechanical properties of D6AC steel plates and laser welds

\begin{tabular}{|c|c|c|c|c|c|c|}
\hline \multirow[b]{2}{*}{ Properties } & & \multicolumn{5}{|c|}{ Tempering temperature $\left({ }^{\circ} \mathrm{C}\right)$} \\
\hline & & $400\left({ }^{\circ} \mathrm{C}\right)$ & $450\left({ }^{\circ} \mathrm{C}\right)$ & $500\left({ }^{\circ} \mathrm{C}\right)$ & $550\left({ }^{\circ} \mathrm{C}\right)$ & $600\left({ }^{\circ} \mathrm{C}\right)$ \\
\hline \multirow[t]{2}{*}{ Yield strength (YS, MPa) } & $\mathrm{P}^{*}$ & 1480 & 1421 & 1362 & 1294 & 1255 \\
\hline & $\mathrm{W}+$ & 1431 & 1362 & 1333 & 1274 & 1251 \\
\hline \multirow{2}{*}{ Ultimate tensile strength (UTS, MPa) } & $\mathrm{P}$ & 1637 & 1539 & 1460 & 1411 & 1343 \\
\hline & $\mathrm{W}$ & 1519 & 1470 & 1421 & 1352 & 1294 \\
\hline \multirow[t]{2}{*}{ Elongation (\%) } & $\mathrm{P}$ & 8.7 & 9.3 & 10.5 & 11 & 12.6 \\
\hline & W & 3 & 4.3 & 6.5 & 8 & 9.6 \\
\hline 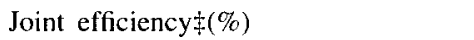 & & 92.8 & 95.5 & 97.3 & 95.8 & 96.4 \\
\hline \multirow{2}{*}{ Charpy impact (Joules) } & $\mathrm{P}$ & 4.5 & 5.8 & 6.2 & 7.8 & 9.5 \\
\hline & $\mathrm{W}$ & 7.25 & 8 & 8.5 & 9.5 & 11.5 \\
\hline
\end{tabular}

Note that: all welded specimens were fractured in the overtempering zone

*P, Steel plate.

$\dagger \mathrm{W}$, Weldment.

$\ddagger$ Joint efficiency, UTS of the weld/UTS of the base metal. 
Both the microstructural and the stress ratio $(R)$ effects were also evaluated. Fractographic examinations were performed on several postweld heat treated specimens to correlate the fracture mode in each region of the weld.

\section{EXPERIMENTAL PROCEDURES}

The chemical composition of the D6AC steel $(3.4 \mathrm{~mm}$ thick) in weight percent was $0.45 \mathrm{C}, 0.24 \mathrm{Si}, 0.83 \mathrm{Mn}$, $0.66 \mathrm{Ni}, 1.09 \mathrm{Cr}, 0.77 \mathrm{Mo}, 0.058 \mathrm{~V}, 0.01 \mathrm{P}$ and $0.008 \mathrm{~S}$. The steel plates were austenized at $926^{\circ} \mathrm{C}$ for $40 \mathrm{~min}$ and then quenched in $80^{\circ} \mathrm{C}$ oil. After quenching, the plates were tempered at $400^{\circ} \mathrm{C}, 450^{\circ} \mathrm{C}, 500^{\circ} \mathrm{C}, 550^{\circ} \mathrm{C}$ and $600^{\circ} \mathrm{C}$ for $2 \mathrm{~h}$. A Rofin-Sinar RS850 $5 \mathrm{~kW} \mathrm{CO}$ laser was utilized for laser welding. Table 1 shows the laser welding variables used in this study. After welding, PWHTs were conducted on the welds at $400^{\circ} \mathrm{C}$, $500^{\circ} \mathrm{C}$ and $600^{\circ} \mathrm{C}$ for $2 \mathrm{~h}$ in a salt bath. The specimens for tensile and Charpy impact testing were made according to the specifications of ASTM E8 and E23 (subsize, $3.0 \mathrm{~mm}$ thick), respectively. The strain rate of tensile tests was $7 \times 10^{-4} \mathrm{~s}^{-1}$. The FCGR tests were conducted on a computerized MTS machine at room temperature. The compact-tension (CT) specimens were used and the experimental procedures meet the standard of ASTM E647-91 ${ }^{17}$. The loading frequency was $20 \mathrm{~Hz}$ with a constant amplitude sinusoidal waveform of the applied load. The stress ratios, the ratio of minimum to maximum load, were 0.1 and 0.25 . The testing software ( 759.40 crack growth test) developed by MTS was used. The crack growth directions were aligned either parallel or normal to the welding direction in the CT specimens (Figure I), namely P-Weld or $\mathrm{N}$ Weld specimens, respectively. In case of a $\mathrm{N}$-Weld specimen, the distance between the notch tip and the bottom fusion line of the weld was about $6.0 \mathrm{~mm}$. Metallographic observations and microhardness measurements were made to identify each region of the weld. Fractographic examinations associated with various regions in laser welds were carried out by a scanning electron microscopy (SEM). The crack path in various regions of a weld was examined by using a technique analogous to 'plateau etching'. ${ }^{18}$ This technique made it possible to simultaneously reveal the fracture surface and the corresponding crack path in the regions concerned.

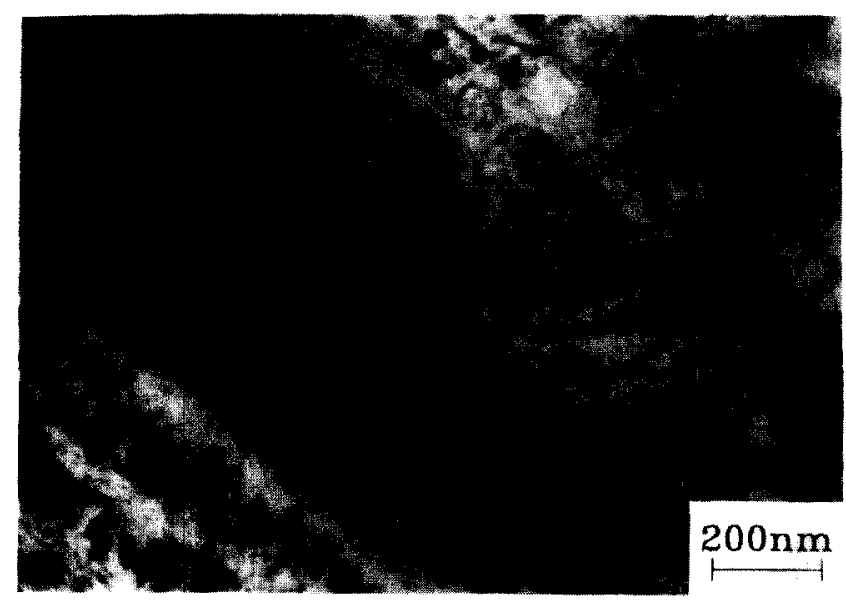

Figure 3 Transmission electron micrograph of the WM showing lower bainite and tempered martensite in the as-welded condition

\section{RESULTS AND DISCUSSION}

The TTT curve of D6AC indicates that the Ms temperature is approximately $300^{\circ} \mathrm{C}\left(570^{\circ} \mathrm{F}\right) .^{\prime}$ In a previous study, ${ }^{19}$ Ms was found to be lowered for the welds. If sufficient weld preheating was provided, the transformation of austenite would change to bainite or mixed structures of bainite and tempered martensite. As austenite transformed to such structures, toughness of the welds could be improved significantly. The microhardness distributions of the laser welds after various PWHTs are displayed in Figure 2. The coarse-grained HAZ exhibited a slightly greater hardness than that of $\mathrm{BM}$ and $\mathrm{WM}$, in spite of tempering at different
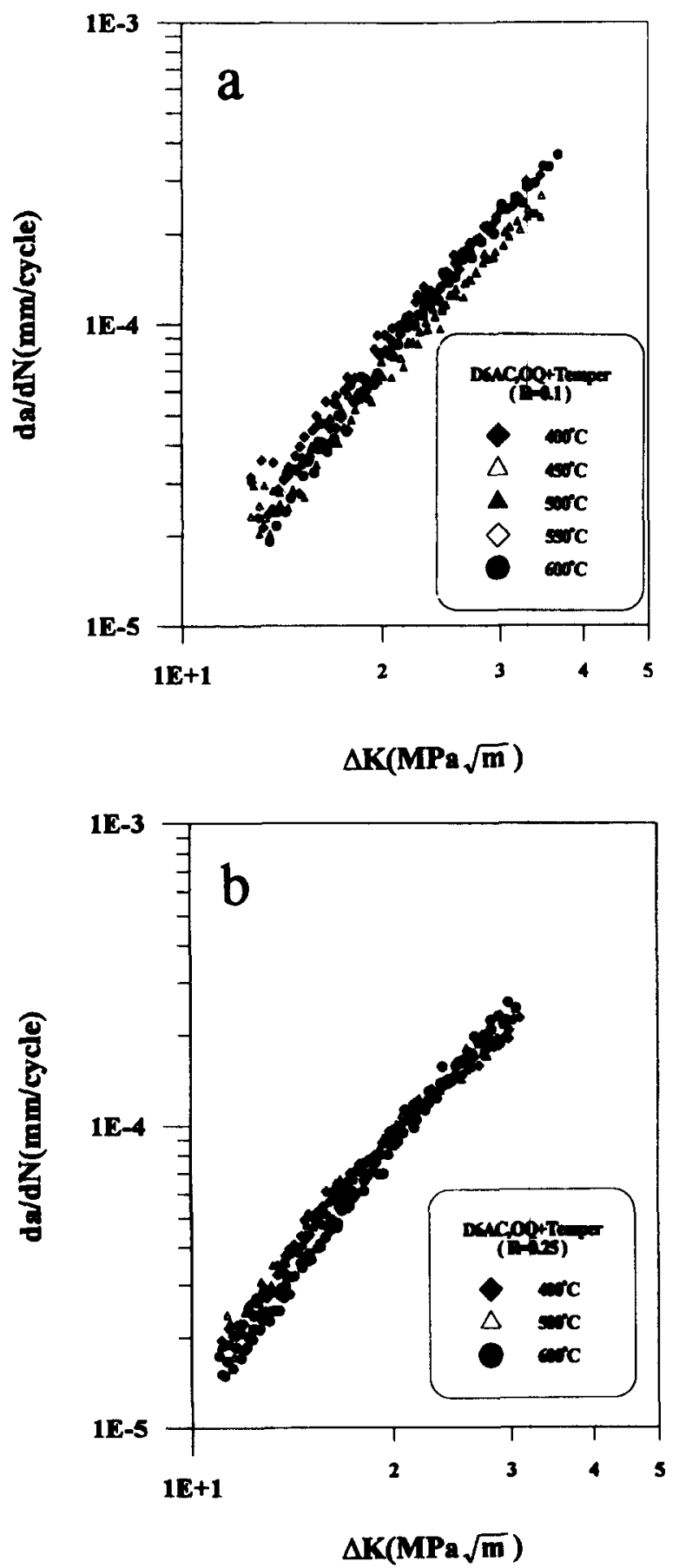

Figure 4 Relationship between crack growth rate $(\mathrm{d} a / \mathrm{d} N)$ and stress intensity factor range $(\Delta K)$ of D6AC steel plates with various PWHTs at (a) $R=0.1$ and (b) $R=0.25$ 
temperatures. The high temper resistance of D6AC steel $^{8}$ would also minimize the extent of the overtempering zone. In general, the hardness of the welds decreased with increasing the tempering temperature. Table 2 shows the mechanical properties of D6AC steel plates and laser welds. It reveals that the strength decreased, while the elongation and impact energy increased, with increasing the tempering temperature. At a given tempering temperature, the strength of the steel plates was higher than that of laser welds. Necking in the overtempering zone was observed, resulting in an overall reduction in the elongation and strength

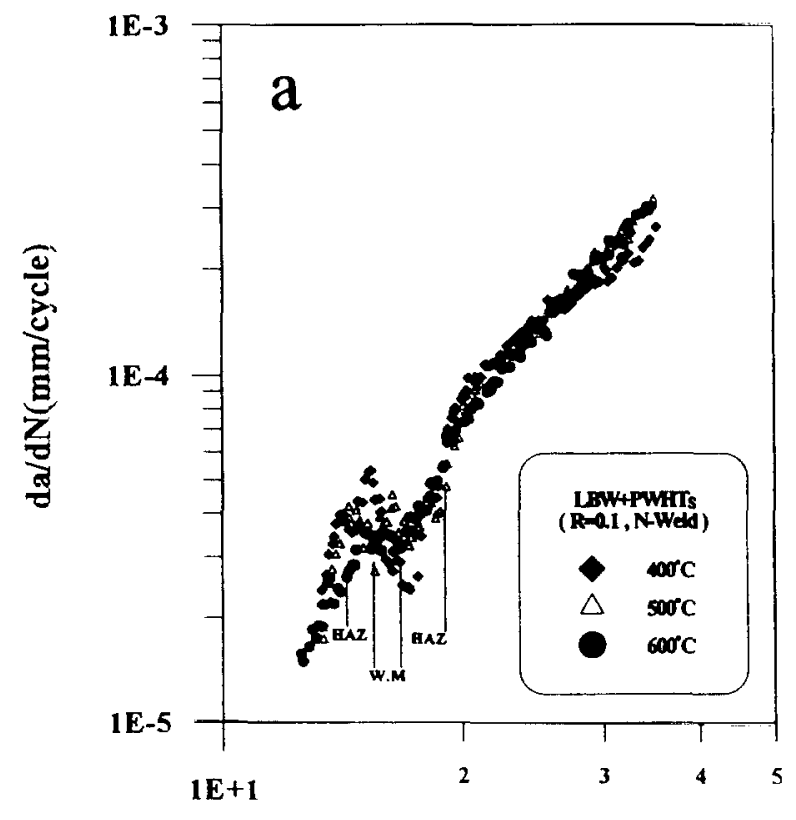

$\Delta K(\mathrm{MPa} \sqrt{\mathrm{m}})$

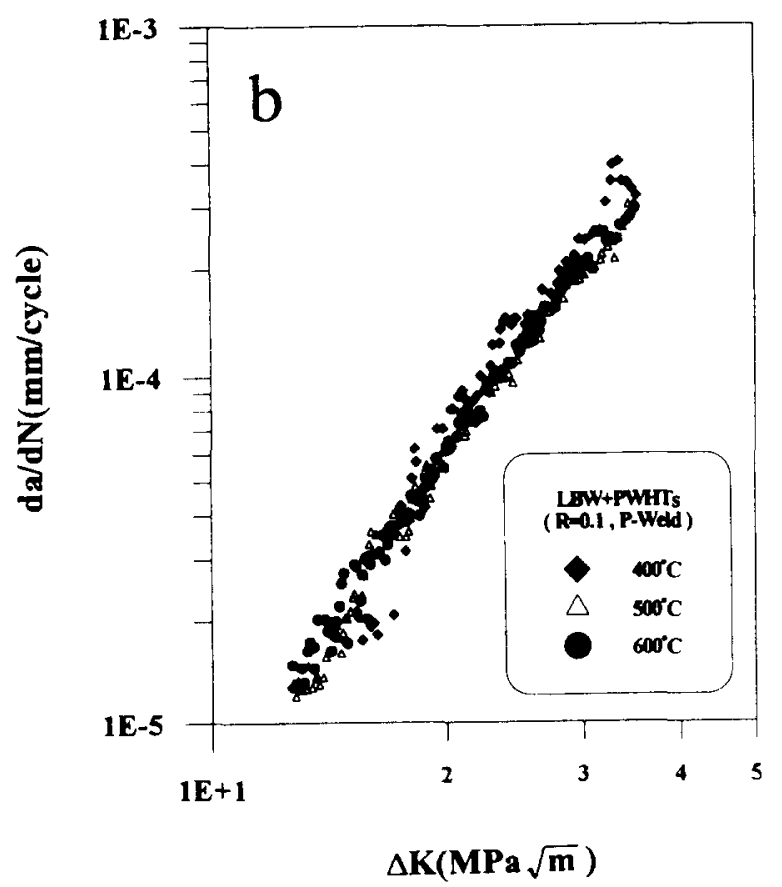

Figure 5 Relationship between crack growth rate $(\mathrm{d} a / \mathrm{d} N)$ and stress intensity factor range $(\Delta K)$ of D6AC laser welds after various PWHTs at $R=0.1$ for (a) N-Weld specimens and (b) P-Weld specimens of the welds. However, the weld joint efficiency was still in excess of $92 \%$. SEM examinations of tensilefractured surfaces revealed a ductile dimple fracture for all specimens.

In this work, laser welding was carried out with $225^{\circ} \mathrm{C}$ preheating and maintained at this temperature for $1 \mathrm{~h}$ after welding to avoid cold cracking of the workpiece. Microstructural observations of the WM in the as-welded condition showed that lower bainite and tempered martensite are presented (Figure 3), in which at least two orientations of carbides in tempered martensite are revealed. The impact toughness of the WM increased with increasing the tempering temperature,
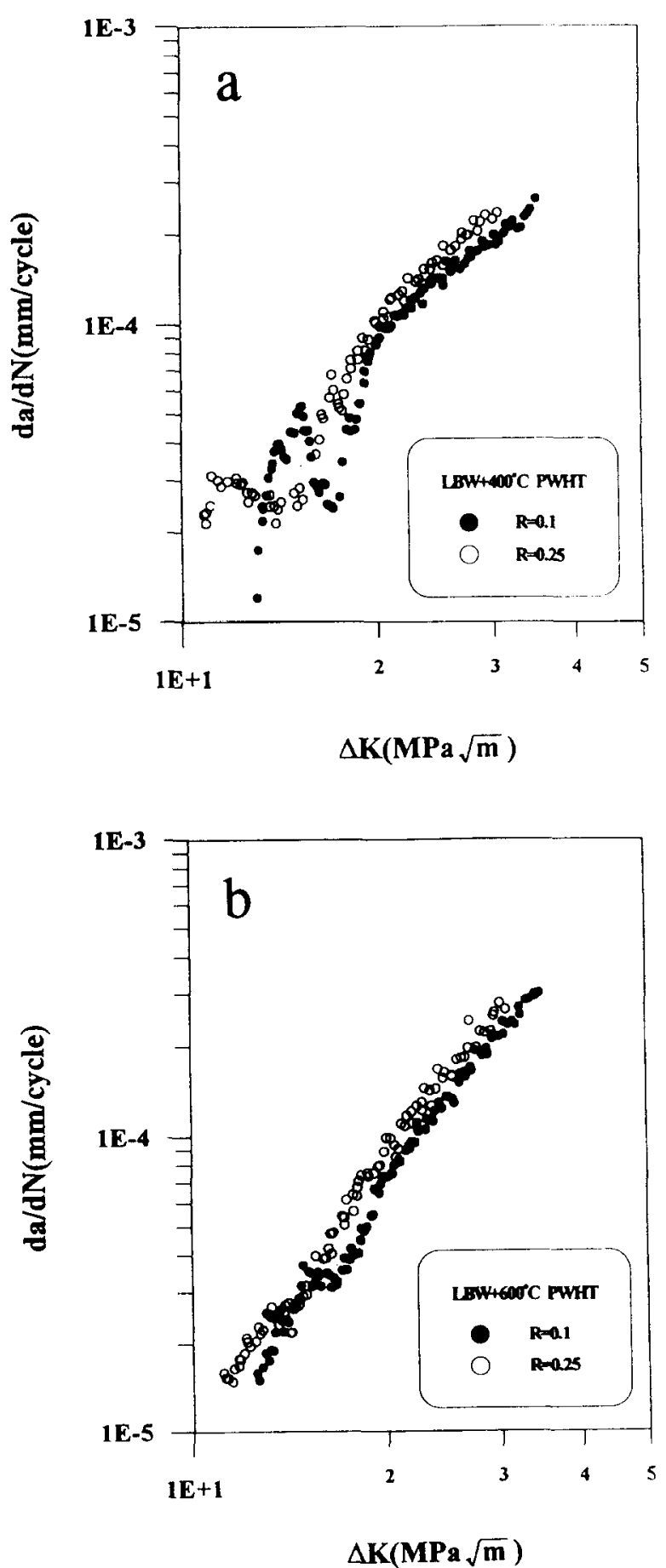

Figure 6 Crack growth rate $(\mathrm{d} a / \mathrm{d} N)$ plotted against stress intensity factor range $(\Delta K)$ for the N-Weld specimen after (a) $400^{\circ} \mathrm{C}$ and (b) $600^{\circ} \mathrm{C}$ PWHTs 
and was always higher than that of the BM. SEM fractographs of the impact specimens showed that the fracture appearance changed from quasi-clevage $\left(400^{\circ} \mathrm{C}\right.$ tempered specimens) to dimples $\left(600^{\circ} \mathrm{C}\right.$ tempered specimens) as the tempering temperature increased. Notvest ${ }^{19}$ indicated that bainite could provide not only the cracking resistance but also good ductility. In addition, refined inclusions in the fusion zone of laser welds could be obtained, i.e. the fusion zone purification effect. ${ }^{20,21}$ Hence, the toughness of laser welds would be better than that of the steel plates.

The FCGR or $\mathrm{d} a / \mathrm{d} N$ as a function of $\Delta K$ for D6AC steel plates after various tempering treatments is given in Figure 4, where the FCGR decreases with increasing the tempering temperature from 400 to $600^{\circ} \mathrm{C}$. In the regime of $\Delta K<20 \mathrm{MPa} \mathrm{m}^{1 / 2}$, the specimen with $600^{\circ} \mathrm{C}$ tempering treatment showed a slightly lower FCGR than other tempered specimens (Figure 4a). As $R$ increased from 0.1 to 0.25 , a slight increase in FCGRs resulted for several tempered specimens (Figure $4 b$ ).
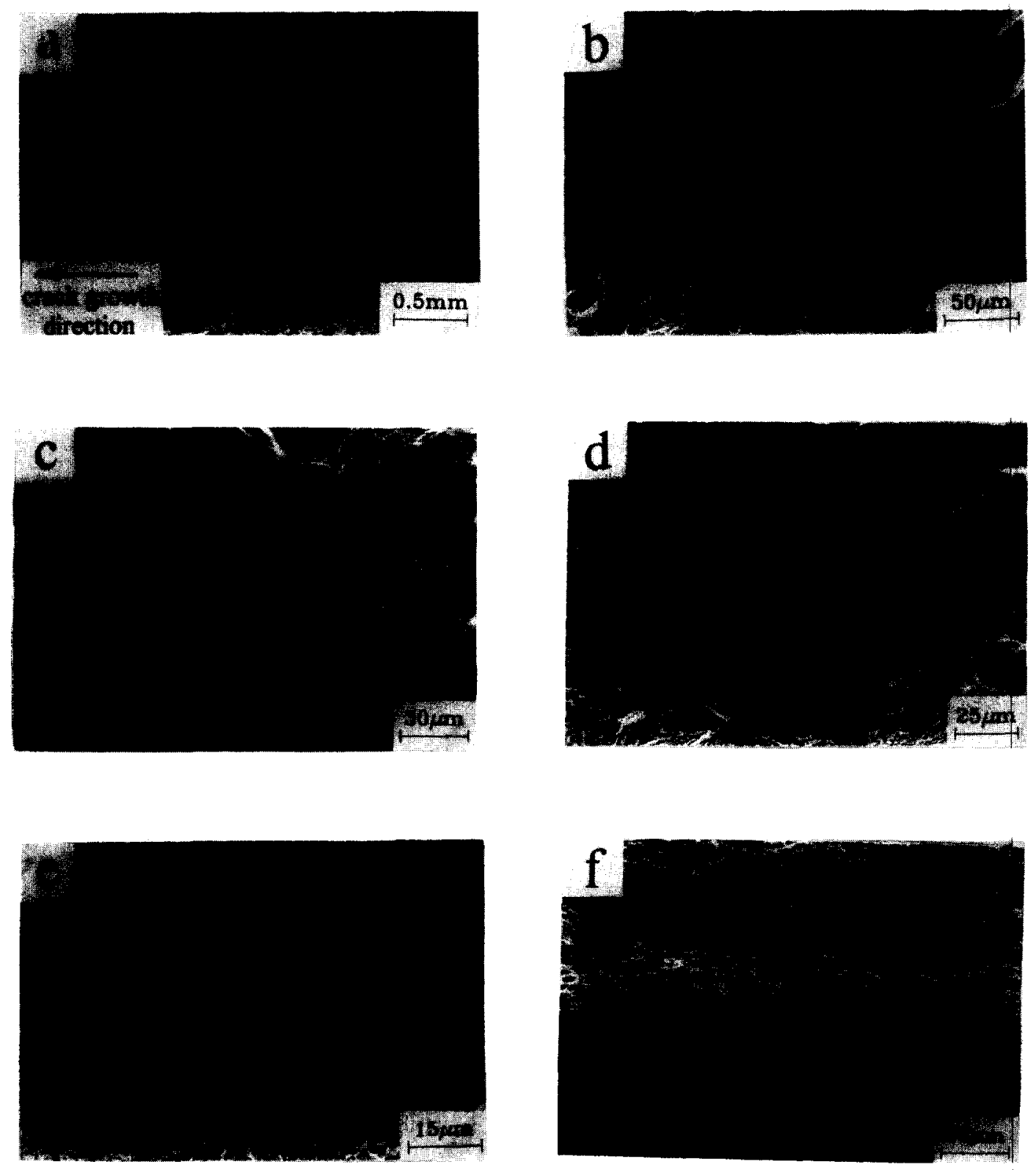

Figure 7 SEM fractographs of a $\mathrm{N}$-Weld specimen tempered at $500^{\circ} \mathrm{C}$ showing: (a) the fracture appearance in various regions of the weld (b) the fracture surface in the WM; (c) the fracture path in the WM; (d) the fracture appearance in the HAZ; (e) the fracture appearance in the $\mathrm{BM}$; and (f) the fracture path in the BM 
retarded the crack growth most among various regions in a weld. However, the trend in decreasing of FCGRs was not so obvious for specimens tempered at a higher temperature, e.g. $600^{\circ} \mathrm{C}$. Figure $5 b$ is the fatigue growth characteristics of all WM at $R=0.1$, in which the WM had a lower FCGR than that of the BM. As the $R$ ratio increased from 0.1 to 0.25 , the $\mathrm{d} a / \mathrm{d} N$ vs $\Delta K$ curves for $\mathrm{N}$-Weld specimens are shown in Figure 6. The increase in $R$ or the PWHT temperature would reduce the extent of the $\mathrm{d} a / \mathrm{d} N$ dip in the HAZ and the WM. In addition, the dip in the curve was not so obvious for the specimen tempered at $600^{\circ} \mathrm{C}$ as shown in Figure $6 b$.

It has been reported that intergranular and transgranular fractures appeared on D6AC specimens if $\Delta K$ was in the range of $7.2-17.6 \mathrm{MPa} \mathrm{m}{ }^{1 / 2} .{ }^{22}$ Similar observations were found in this work. Futhermore, the amount of intergranular fracture decreased slightly with increasing tempering temperature for identical $R$ and $\Delta K$ ranges. Figure 7 is the fatigue-fractured appearance of a N-Weld specimen tempered at $500^{\circ} \mathrm{C}$. The low magnification of the fracture surface revealed that the WM exhibited coarse columnar grains with remarkable surface roughness (Figure 7a). The grains near the lower half of the WM were finer and aligned nearly parallel to the crack growth direction. However, the grains in the upper half were coarser and oriented approx. $45^{\circ}$ inclined to the crack growth direction. Figure $7 b$ shows the coexistence of transgranular and intergranular fracture modes in the WM. The zigzag nature of fracture path, which caused by changing crack growth direction repeatly in the WM, is obvious as given in Figure $7 c$. Therefore, the overall decrease in FCGRs could be attributed to the effect of roughness-induced crack closure. ${ }^{23}$ Figure $7 d$ shows the fracture surface of the HAZ, in which the outline of equiaxed grains are also revealed. For the comparison purpose, the fractography and the crack path of the BM are also displayed in Figures $7 e$ and $7 f$, respectively. It is worthwhile to mention that the crack path in the $\mathrm{BM}$ is rather smooth. For $\mathrm{N}$-Weld specimens, the appearance of fracture surfaces did not change much with $R$ ratios and tempered conditions.

The solidified structure of the WM reveals that columnar grains with two major growth directions impinged at the centreline $\left(\mathrm{AA}^{\prime}\right)$ as indicated in Figure 7a. Figure $8 a$ is the fracture appearance for a P-Weld specimen tempered at $500^{\circ} \mathrm{C}$ under $R=0.1$. It is noted that the crack front was perpendicular to the plane of Figure $7 a$, and near the impinged line ( $\left.\mathrm{AA}^{\prime}\right)$ for P-Weld specimens. Figure $8 b$ shows the fractograph of the upper half WM, where transgranular and intergranular fractures are clearly revealed and the zigzag crack in nature can also be seen from the surface roughness in Figure $8 a$. On the other hand, the zigzag crack path with less in amplitude and more transgranular fracture in the lower half WM is observed as indicated in Figure $8 \mathrm{c}$. The difference in fracture appearance in the WM would be contributed to the orientation of columnar grains with respect to the crack growth direction.

\section{CONCLUSIONS}

1. The FCGRs decreased with increasing the tempering temperature from 400 to $600^{\circ} \mathrm{C}$ for both $\mathrm{D} 6 \mathrm{AC}$
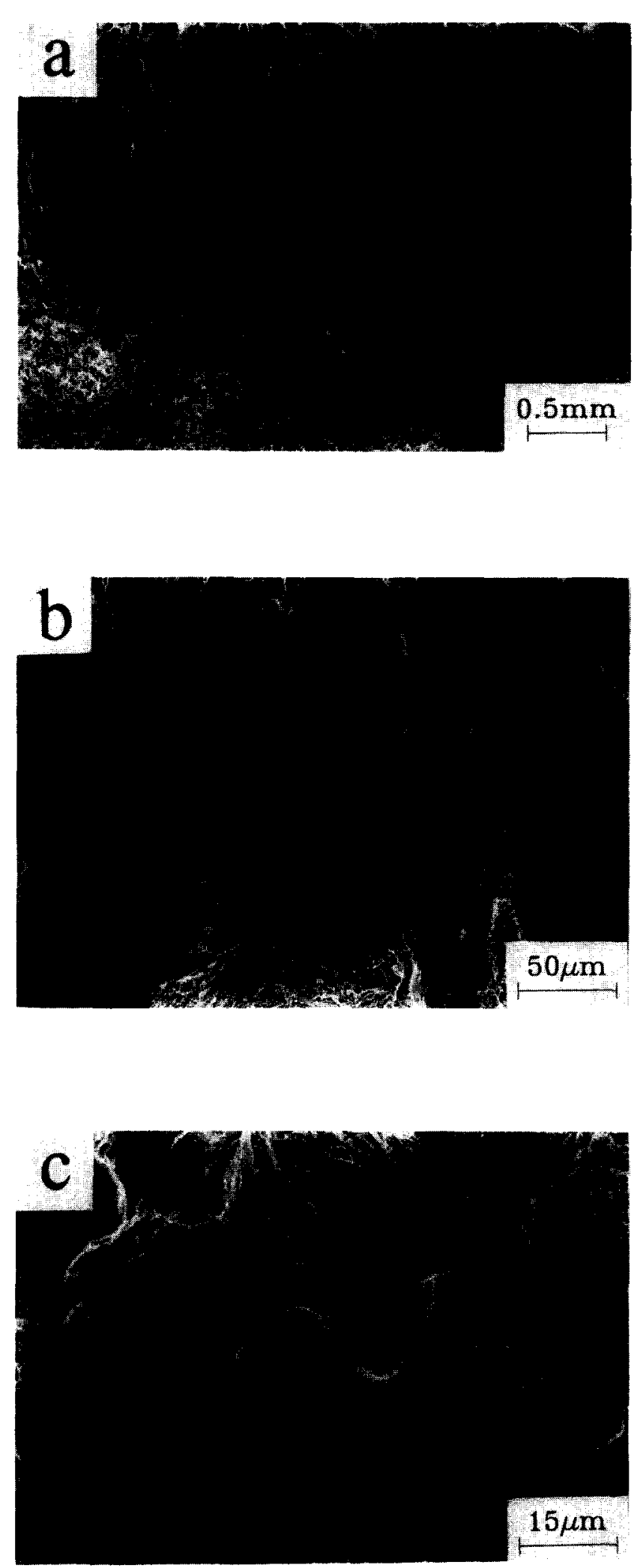

Figure 8 SEM fractographs of a P-Weld specimen tempered at $500^{\circ} \mathrm{C}$ showing: (a) the low magnification of fracture appearance: (b) the fracture surface in the upper half WM; and (c) the fracture surface in the lower half WM

steel plates and laser welds. As the $R$ ratios increased from 0.1 to 0.25 , a slight increase in FCGRs was observed.

2. The FCGRs of the WM and the HAZ were less than those of the $\mathrm{BM}$ for similar $\Delta K \mathrm{~s}$. The dip in the $\mathrm{d} a / \mathrm{d} N$ vs $\Delta K$ curve in regions of the $\mathrm{HAZ}$ and 
the WM was less in extent as the PWHT temperature of the weld increased. Similar observation was found for increasing the $R$ ratio in the experiment.

3. The formation of lower bainite and tempered martensite in the WM and the HAZ during welding of D6AC with $225^{\circ} \mathrm{C}$ preheating not only retarded the fatigue crack propagation, but also improved the Charpy toughness in these regions.

4. Fractographic examinations indicated that the existence of transgranular and intergranular fracture modes was present in the WM of laser welds. The zigzag nature of the crack propagation, resulting in a roughness-induced closure, would contribute to a lower FCGR of that region.

\section{ACKNOWLEDGEMENTS}

The authors gratefully acknowledge the support of the Republic of the Chinese National Science Council (Contract Nos NSC83-0405-E019-005 and NSC840405-E019-001).

\section{REFERENCES}

Peterman, G.L. Met. Progr. 1965 87(2), 80-83

Peterman, G.L. Met. Progr. 1966 89(2), 73-76

Meitzner, C.F. and Stout, R.D. Weld J. 1966 45, 393S-400S

Kearns, W.H., Semmel, J.W. and Marble, J.D. Weld J. 1960 39, $484 S-492 S$

5 Travis, R.E., Ardito, V.P. and Adams, C.M. Jr. Weld J. 1963 42, 9S-17S
6 Clark, R.E. and Privoznik, L.J. Weld J. 1965 44, 199S-210S

7 Mchenry, H.I., Collins, J.C. and Key, R.E. Weld J. 1966 45, 419S-425S

8 Mchenry, H.I., Collins, J.C. and Key, R.E. Weld J. 196746 337S-342S

9 Key, R.C., Collins, J.C. and Mchenry H.I. Weld J. 196746 , 991-1000

10 Lancaster, J.F. 'The Physics of Welding', Pergamon, Oxford, 1984, pp. $269-290$

11 Paris, P. and Erdogran, F. ASME J. Basic Engng 196385 , 528-534

12 Bryan, R.H., Holz, P.P., Iskander, S.K., Merkle, J.G. and Whitman, G.D. Trans. ASME J. Press. Ves. Tech. 1981 103, 85-93

13 Tsay, L.W., Li, Y.M., Chen, C. and Cheng, S.W. Int. J. Fatigue 1992 14, 239-247

14 Dolby, R.E. Met. Const. Br. Weld J. 1972 4(2), 59-63

Bailey, N. Met. Const. Br. Weld J. 1971, 33, 104-107

Dolby R.E. Met Const Br. Weld J. 1971, 33, 99-103

'Standard Test Method for Measurement of Fatigue Crack Growth Rates' 1991, Annual Book of ASTM Standards, E64791 Vol 03.01, ASTM, Pennsylvania, pp 654-681

18 Chestnutt, J.C. and Spurling, R.A. Met. Trans. A 1977, 8A 216-218

19 Notvest, K. Weld J. 1966 45, 173S-177S

20 Breinan, E.M. and Banas, C.M. 'Fusion zone purification during welding with high power $\mathrm{CO}_{2}$ laser', Advance Welding Technol. 2nd Int. Symp. Jap. Welding Soc., Osaka, Japan, 24-28 August, 1975

21 Metzbower, E.A. and Moon, D.W. Mechanical properties, fracture toughness and microstructures of laser welds of high strength alloys' Appl. Lasers Mater. Processing, ASM, Ohio. 18-20 April, 1979, pp. 83-100

22 Liaw, P.K., Peck, M.G, and Rudd, G.E. Engng Fract. Mech. $1992,43,379-400$

23 Suresh, S. and Ritchie, R.O. Met. Trans. A 1982, 13A, 16271631 